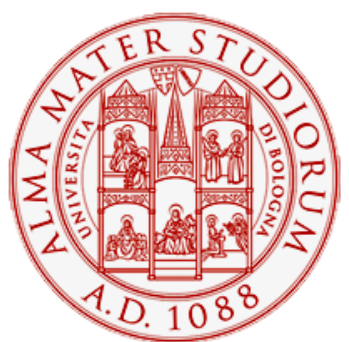

Alma Mater Studiorum - Università di Bologna DEPARTMENT OF ECONOMICS

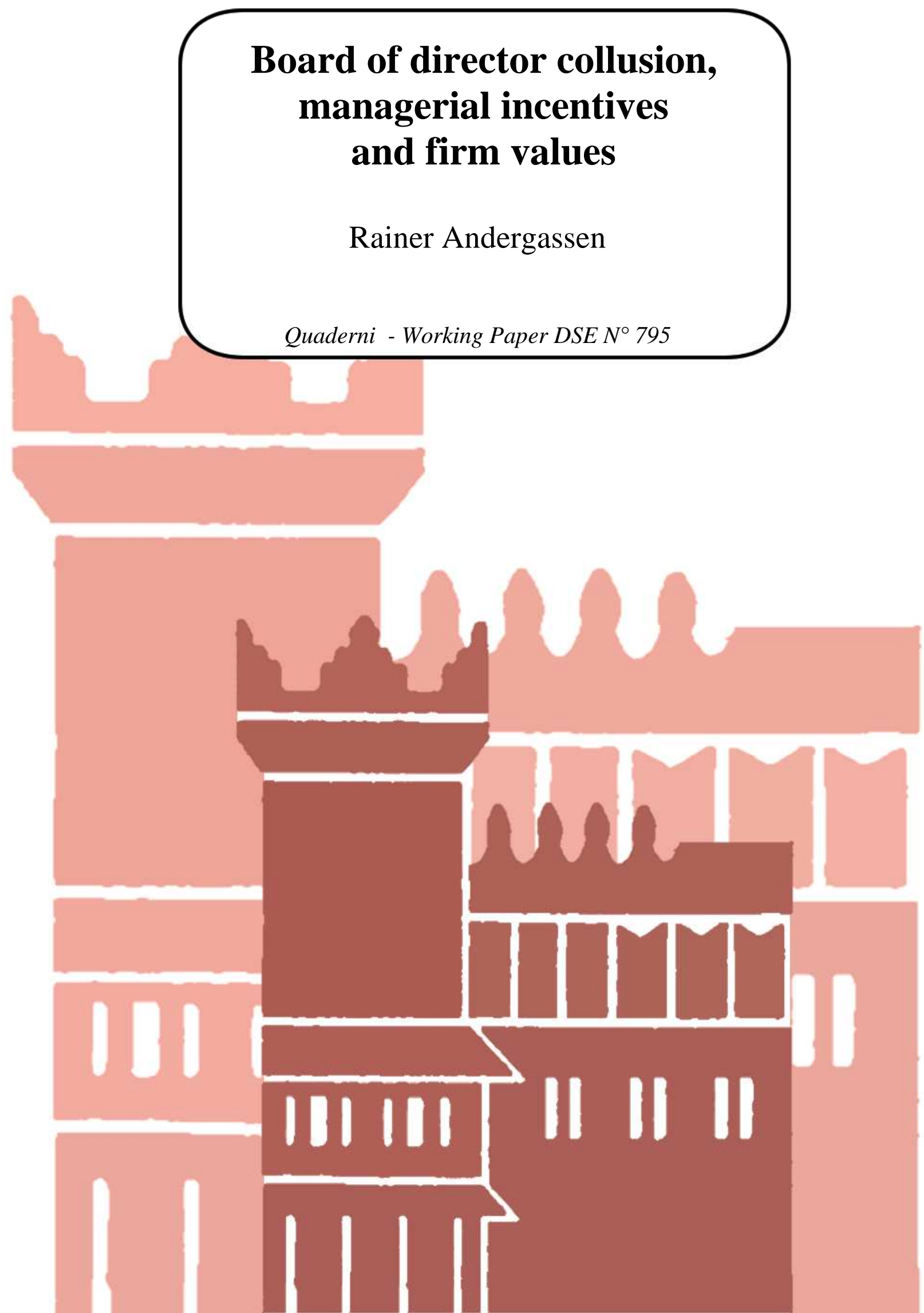




\title{
Board of director collusion, managerial incentives and firm
}

\section{values}

\author{
Rainer Andergassen*
}

October 27, 2011

Department of Economics, University of Bologna, Piazza Scaravilli 2, 40126, Bologna, Italy

RCEA, Rimini Center for Economic Analysis, Italy

\begin{abstract}
This paper investigates the effects of board of director collusion on managerial incentives and firm values. Recent academic research hints at the social network of board of directors as an important conduit for coordinating corporate governance policies, such as managerial pay, and curbing competition. We study a model where managers can exert unobservable cost-cutting effort and investigate the consequences of and the incentives for coordinating managerial pay among corporate boards.
\end{abstract}

Keywords: Board of director collusion; managerial incentives; pay-for-performance sensitivity; firm values; managerial pay.

JEL: L1; J33; O31; M52

*E-mail: rainer.andergassen@unibo.it 


\section{Introduction}

Recent academic research hints at the social network of the board of directors as a vehicle for sharing information and coordinating and propagating corporate governance policies, in particular, CEO compensation practices. For example, Bizjak, Lemmon and Whitby (2009) provide evidence that the network of board of directors helped spread the practice of backdating stock options granted to executives. Barnea and Guedj (2009) and Renneboog and Zhao (2011) show that stronger board connectedness leads to higher CEO compensation levels and a weaker pay-for-performance sensitivity. The board of directors has primary authority over the level and structure of executive compensation and therefore can affect competition among firms by tailoring managerial incentives. Direct and indirect ties between boards can thus be an important conduit for curbing competition and promoting collusion among firms (Dooley, 1969; Koenig, Gogel, and Sonquist, 1979; Burt, 1983).

In this paper we investigate the effects of board of director collusion on managerial pay-forperformance sensitivities and firm values. We consider a model with horizontally differentiated products (Salop, 1979). Firms are run by risk-neutral ${ }^{1}$, effort-averse managers who are identical in talent and exert unobservable cost-cutting effort. We consider pay-for-performance schemes in which managerial pay is linearly tied to firm profits. We show that if boards define compensation packages independently to maximize firm values, then complete delegation, that is, a one to one relationship between firm profits and managerial compensation, is optimal. This outcome is suboptimal from the shareholders' and the managers' viewpoint since it provides managers with too strong incentives, leading to too fierce competition among firms. The reason is that boards increase the pay-for-performance sensitivity trying to steal market share from neighboring firms, thereby increasing the strength of competition among firms. We then consider the case where boards choose managerial pay in a coordinated way (board collusion), and investigate how this affects firm values. We show that board collusion reduces the firms' endeavor to steal market share from neighbors through incentive provision, leading to lower pay-for-performance sensitivities ${ }^{2}$, which is in keeping with empirical findings in Barnea and Guedj (2009) and Renneboog and Zhao (2011), and that the pay-for-performance sensitivity is increasing in the degree of product market competition (PMC), which is in accordance with empirical evidence documented in Cuñat and Guadalupe (2005, 2009a, 2009b) and Karuna (2007).

\footnotetext{
${ }^{1}$ We abstract for simplicity from the traditional agency problem in which a risk-neutral shareholder interacts with a risk-averse manager and focus instead on the relationship between board of director collusion, managerial incentives and firm values.

${ }^{2}$ Similar qualitative results are obtained if firms compete in quantities.
} 
The remaining part of the paper is organized as follows. In Section 2 we review the literature on the subject. In Section 3 we introduce the basic model and show that if boards choose managerial pay independently, then complete delegation is optimal. In Section 4 we analyze the case of board collusion which is modeled in a reduced form, using the conjectural variations equilibrium, and investigate how different degrees of coordination among corporate boards affect managerial pay-for-performance sensitivities and firm values ${ }^{3}$. In Section 4.1 we consider the case of symmetric collusion in which the degree of board coordination through direct and indirect ties is the same for all boards and show that the stronger board collusion is, the lower pay-for-performance sensitivities and the larger firm values. In Section 4.2 we consider the case of asymmetric collusion, in which boards are divided into a group of strongly coordinated boards (corporate elite) and a group of weakly coordinated boards (corporate dregs) and study how within- and between-group coordination affect managerial pay-for-performance sensitivities and firm values. We first investigate the case in which between-group collusion is negligible and show that pay-for-performance sensitivities and firm values are lower in the more influential boards, that is, those boards whose coordination with other boards is on average stronger. Since board influence depends on the strength of board collusion as well as on the group's size, it may happen that the group of strongly coordinated boards is less influential than the group of weakly coordinated boards if the former group is sufficiently small. We further show that strengthening board coordination of either group always increases firm values and that if the corporate elite is more influential than the corporate dregs, then increasing the size of the former group increases the firm value of all firms but the one switching from the latter to the former group. We then study the case in which between-group collusion is non-negligible, assuming that it is weaker than collusion among the corporate elite but stronger than collusion among the corporate dregs. We show that under this assumption the corporate elite is always more influential than the corporate dregs and hence that pay-for-performance sensitivities and firm values are lower in the former group than in the latter one. We find that stronger collusion among the corporate elite increases the pay-for-performance sensitivity in the corporate dregs and that stronger collusion among the corporate dregs reduces the pay-for-performance sensitivity in the corporate elite. A consequence of this result is that there exists an inverted- $U$ relationship between the value of firms belonging to the corporate elite and the degree of collusion among its members and that it is therefore

\footnotetext{
${ }^{3}$ Among the determinats of composition and size of corporate boards are the coordination of corporate policies, the collection and extraction of information and the monitoring of the management's activity (see, for example, Raheja, 2005 and Renneboog and Zhao, 2011). Since we focus only on the incentives and the effects of managerial pay coordination we consider the degree of board coordination as an exogenously defined variable. Nevertheless, we investigate how a change in the degree of board coordination affects firm values, which provides an indication on the boards' incentive to increase or decrease coordination.
} 
never optimal for the corporate elite to choose a pay-for-performance sensitivity that maximizes joint profits. The reason for this is that if board collusion is sufficiently strong, then the gains from a further strengthening of collusion, which are due to weaker competition among its members, are outweighed by the losses due to stronger competition from the corporate dregs. On the other hand, we show that expanding the size of the corporate elite benefits all firms but the one joining the elite as long as between-group collusion is weak. Section 5 provides some concluding remarks. All proofs are collected in the Appendix.

\section{Literature Review}

There is a burgeoning literature on board of directors networks and their effects on corporate governance ${ }^{4}$. Canyon and Muldoon (2006) and Davis, Yoo and Baker (2003) show that the mean geodesic (or characteristic length) in director networks, that is, the average shortest path length between two boards, is very small and conclude that the director network may be an important conduit for spreading information and rumors across boards. In particular, Canyon and Muldoon (2006) find that the mean geodesic of the board of directors network of publicly traded firms in February 2003 in the US is 4.33 whereas the number of boards is 1733 , while Davis, Yoo and Baker (2003), using data on Fortune 500 firms from 1982, 1990 and 1999, find a characteristic length of 3.38, 3.46 and 3.46 at the three time points. Barnea and Guedj (2009) map the entire board of director network of S\&P 1500 firms between 1996 and 2004 and investigate the relationship between membership in the network and directors' decision-making. Their major findings are that the stronger the board connectedness of a firm is, the higher the CEO's compensation, the lower the CEO's pay-for-performance sensitivity and the lower the probability that CEOs of poorly performing firms are fired. Renneboog and Zhao (2011) study the network of listed UK firms from 1996 to 2007 and find that more direct board connections lead to a weaker pay-for-performance sensitivity. Larcker et al. (2005) calculate the minimum number of other company boards for establishing a link between two directors (back door distance) and find a statistical negative relation between the back door distance between inside and outside directors and CEO compensation levels. Restricting their analysis to direct links between boards (i.e. board

\footnotetext{
${ }^{4}$ The board of director network as a vehicle for sharing information is studied in Haunschild (1993) and Haunschild and Beckman (1998) in the context of acquisitions; in Stuart and Yim (2010) where private equity-backed take-private operations are studied; in Davis (1991) and Davis and Greve (1997) in relationship with the adoption of poison pills and golden parachutes; in Bizjak, Lemmon and Whitby (2009) where the backdating of options are studied; in Kuhnen (2009) where the role of the network in the mutual fund industry is examined; in Chiu, Teoh and Tian (2010) where the contagious behavior of earnings management is inquired.
} 
interlocks), Hallock (1997) and Fich and White (2003) find evidence that board connections positively affect CEO compensation levels, and Fich and White (2003) find a negative association between the number of interlocking directorships and CEO turnover probability.

Our paper is also related to the strand of literature that discusses the strategic advantage of delegation in the presence of separation of ownership and management (see, for example, Vickers, 1985; Fershtman, 1985; Fershtman and Judd, 1987; Sklivas, 1987; Fershtman, Judd and Kalai, 1991; Spagnolo, 2000; Aggarwal and Samwick, 1999; Kedia, 2006). Vickers (1985) points out that it is not necessarily optimal that the agent and the principle maximize the same objective function. Fershtman and Judd (1987) and Sklivas (1987) consider compensation contracts that are linear in profits and sales revenues and examine how competing owners strategically manipulate managerial incentives and how this affects the oligopoly outcome. Aggarwal and Samwick (1999) argue that, in a strategic environment, the use of relative performance evaluation to filter out common industry shocks may be limited by the need to soften PMC. Joh (1999) demonstrates that managerial incentive contracts can act as commitment devices to further collusion. Spagnolo (2000) shows that as long as agents in the financial markets have rational expectations, stock based managerial compensation greatly facilitates tacit collusion in repeated oligopoly games. While this literature focuses on the strategic advantage and the effects of pre-commitment in delegation games, we investigate the firms' incentives to coordinate the degree of delegation (that is, managerial pay and in particular managerial pay-forperformance sensitivities) with the aim to reduce competition and thus to boost firm values. Hansen and Lott (1996) argue that shareholders holding a diversified portfolio pursue portfolio instead of firm value maximization and thus device corporate policies that internalize between-firm externalities. In our paper between-firm externalities are internalized through board of director connections and we analyse how asymmetries in the degree of board coordination affect corporate policies and firm values and show that perfect board coordination, that is, the complete internalization of externalities, is not always a desireable outcome.

The paper contributes to the strand of literature that investigates how PMC affects managerial incentives (see, for example, Schmidt, 1997; Raith, 2003; Vives, 2008). Contrary to this literature we take the extent of delegation explicitly into account and show that, in addition to the direct effects pointed out in Raith (2003), managerial incentives are also affected indirectly through changes in the pay-for-performance sensitivity.

Our results are in keeping with the positive relationship between the pay-for-performance sensitiv- 
ity and the degree of PMC found in recent empirical studies. Cuñat and Guadalupe (2005) exploit the quasi-natural experiment of the pound sterling appreciation in 1996 to investigate the effect of an exogenous variation in the degree of competition on incentives. They find that stronger competition increases the steepness of performance-related pay. Cuñat and Guadalupe (2009a) use the deregulation of the banking and financial sectors in the 1990s as a quasi-natural experiment and find similar results, while Cunat and Guadalupe (2009b) find that an increase in foreign competition reduces nonperformance-related pay and increases pay-for-performance sensitivity. Karuna (2007) investigates the relationship between total equity incentives and a multi-dimensional characterization of competition, encompassing product substitutability, market size and entry costs, and finds a positive relationship between PMC and pay-for-performance sensitivity.

\section{The model}

We consider $n$ firms, symmetrically distributed around the unit circle, producing a horizontally differentiated product. Firms are run by managers and owned by shareholders, which are represented by a board of directors. Managers are all identical in talent. Average production costs of firm $i=1, \ldots, n$ are $C_{i}\left(e_{i}\right)=c+\varepsilon_{i}-e_{i}$, where $e_{i}$ is unobservable managerial effort to cut costs and $\varepsilon_{i}$ is an independently identically distributed random variable, continuously distributed over the support $[\underline{\varepsilon}, \bar{\varepsilon}]$, where $\underline{\varepsilon}<0$ and $\bar{\varepsilon}>0$, with mean 0 and variance $\sigma^{2}$. We consider a mass $m$ of consumers uniformly distributed along the unit circle. The representative consumer's utility, given that he is positioned at $x$ and buys $\operatorname{good} i$, is $V_{i}(x)=s-p_{i}-t\left(x-z_{i}\right)^{2}$, where $z_{i}$ is the position of firm $i, t$ is the transportation cost and $s$ is the consumer's gross utility. We assume that $s$ is sufficiently high such that the market is always covered. $t$ can also be interpreted as a measure of product substitutability: the lower $t$ is, the greater the degree of product substitutability.

We assume that shareholders are risk-neutral and that managers are risk-neutral but effort-averse, and we normalize the risk-free interest rate to zero. The manager's utility function is $U\left(W_{i}\right)=$ $W_{i}-\frac{1}{2} k e_{i}^{2}$ and we assume that the compensation package $\left(W_{i}\right)$ consists of a linear combination of cash $\left(w_{i}\right)$ and expected profits $\left(E\left(\pi_{i}\right)\right)$, that is, $W_{i}=\left(1-\alpha_{i}\right) w_{i}+\alpha_{i} E\left(\pi_{i}\right)$, where $\alpha_{i} \in[0,1]$ is the pay-for-performance sensitivity, measuring how managerial pay changes as firm profits vary. The shareholders' aim is to maximize residuals profits $\left(\left(1-\alpha_{i}\right) E(\pi)\right)$ minus cash payments $\left(\left(1-\alpha_{i}\right) w_{i}\right)$, that is, $S_{i}=\left(1-\alpha_{i}\right)\left[E\left(\pi_{i}\right)-w_{i}\right]$ (shareholder or firm value). For $\alpha_{i}=1$ the company is sold to the manager who becomes the residual claimant (complete delegation). We assume that the board's 
incentives are perfectly aligned with those of shareholders.

The timing of the model is as follows. $n$ firms operate in the market. The board of directors of each firm $i=1, \ldots, n$, knowing the probability distribution governing cost shocks, publicly offers a managerial compensation contract. Boards set managerial pay either independently to maximize firm value $S_{i}$ or in a coordinated way (board collusion). We assume that board directors are unable to disentangle the effects of all direct and indirect board ties and we therefore focus on a Bayesian equilibrium $^{5}$. Managers accept the contract if their expected utility is not lower than their outside option utility, which we normalize to zero, and are randomly matched to firms. Once hired, the manager chooses unobservable effort $e_{i}$ and the productivity shock $\varepsilon_{i}$ realizes. We assume that the manager of firm $i$ learns only the realization of $\varepsilon_{i}$ but not the realization of $\varepsilon_{j}, j \neq i$. In the final stage prices are chosen. We assume that managers cannot credibly communicate the true cost once they learn its value.

We define $x \equiv 2 t k \frac{1}{m n}$. Throughout this paper we assume the following.

Assumption 1 Parameter values are such that (i) $x \geq \max \left\{4,1+\frac{m}{k n}\right\}$; (ii) $c>\frac{2}{x-1} \frac{t}{n^{2}}-\underline{\varepsilon}$.

Assumption 1 (i) guarantees that the second order conditions for the problem of the manager and the board of directors are always satisfied; (ii) assures that, in equilibrium, $C_{i}\left(e_{i}\right)>0$ for each firm $i$.

The following proposition can be proved.

Proposition 1 Given the pay-for-performance sensitivity of firm $i\left(\alpha_{i}\right)$ and the expectation about the pay-for-performance sensitivity set by firms $\left(E\left(\alpha_{j}\right)\right)$, managerial effort at firm $i$, its expected demand and firm value are, respectively,

$$
\begin{gathered}
e_{i}=\alpha_{i} \frac{1}{\frac{1}{n} \sum_{j=1}^{n} \frac{x-\alpha_{i}}{x-E\left(\alpha_{j}\right)}} \frac{m}{k n} \\
E\left(d_{i}\right)=\frac{1}{\frac{1}{n} \sum_{j=1}^{n} \frac{x-\alpha_{i}}{x-E\left(\alpha_{j}\right)}} \frac{m}{n} \\
S_{i}=\frac{1}{4 t} n m \sigma^{2}+\left(x-\alpha_{i}^{2}\right) \frac{1}{2 k}\left(\frac{1}{\frac{1}{n} \sum_{j=1}^{n} \frac{x-\alpha_{i}}{x-E\left(\alpha_{j}\right)}} \frac{m}{n}\right)^{2} .
\end{gathered}
$$

The problem of the board of directors is to find $\alpha_{i}$ that maximizes firm value (3). Managerial effort (1) at firm $i$, its expected demand (2) and firm value (3) depend positively on $\alpha_{i}$ and negatively on

\footnotetext{
${ }^{5}$ Board members may have a local knowledge of the network, i.e. direct links among boards, but are not completely aware of all indirect ties, and are thus unable to perfectly anticipate all the repercussions of their decisions.
} 
$E\left(\alpha_{j}\right)$. By increasing the manager's pay-for-performance sensitivity, firms try to "steal" market share from others. We call this the competition-for-demand effect.

We define $\alpha_{i}^{\star} \equiv \operatorname{argmax}_{\alpha_{i}} S_{i}$.

Proposition 2 If boards choose managerial pay independently, then $\alpha_{i}^{\star}=1$, and $S_{i}=S^{I} \equiv \frac{1}{4 t} n m \sigma^{2}+$ $(x-1) \frac{1}{2 k}\left(\frac{m}{n}\right)^{2}$.

Proposition 2 shows that if managerial pay is set in a competitive way, then complete delegation is optimal. Since managers are risk-neutral, complete delegation maximizes the firm value. We show in the next section that this solution is inefficient from the shareholders' viewpoint since it provides the manager with too strong incentives, leading to too fierce competition among firms and, as a result, to too low profits.

\section{Board of director collusion}

We assume that boards coordinate managerial pay decisions through direct and indirect board ties. We model board coordination using a reduced-form, the conjectural variations equilibrium ${ }^{6}$. Let us define $\lambda_{i, j} \equiv \frac{\partial E\left(\alpha_{j}\right)}{\partial \alpha_{i}} \in[0,1]$, for $i, j=1, \ldots, n$, where we assume that $\lambda_{i, j}=\lambda_{j, i}$. We interpret $\lambda_{i, j}$ as the degree of coordination among boards $i$ and $j$ since it captures how a change in $\alpha_{i}$ affects firms' expectation about the value of $\alpha_{j}$. If there are neither direct nor indirect ties between the two boards and thus they choose managerial pay in an uncoordinated way, then $\lambda_{i, j}=0$ and consequently a change in $\alpha_{i}$ does not affect $E\left(\alpha_{j}\right)$. If direct and indirect ties between the two boards are very strong such that the two boards choose managerial pay-for-performance sensitivities to maximize joint profits (perfect board coordination), then $\lambda_{i, j}=1$, and thus a change in $\alpha_{i}$ induces the same change in $E\left(\alpha_{j}\right)$. Intermediate values of $\lambda_{i, j}$ capture intermediate degrees of board coordination, where larger values of $\lambda_{i, j}$ correspond to stronger board coordination. ${ }^{7}$

By choosing $\alpha$, the board of directors trades off gains from higher firm profits, due to greater managerial effort, against the cost for shareholders of inducing a stronger effort level. If $\lambda_{i, j}=1$ for each $i=1, \ldots, n$, then managerial pay decisions are perfectly coordinated, while if $\lambda_{i, j}<1$ for some $i$, then the expected demand of firm $i(2)$ and firm value (3) are increasing in $\alpha_{i}$, and therefore firms try to "steal" market share from others through stronger incentive provision.

\footnotetext{
${ }^{6}$ See also Denicolò and Zanchettin (2010), in which competition among firms is modeled using the conjectural variations equilibrium.

${ }^{7} \lambda_{i, i}$ indicates how a change in $\alpha_{i}$ affects firms' expectations about $\alpha_{i}$, and its value ranges from 0 , in which case board $i$ acts independently, to 1 , in which case all firms are perfectly informed about the board's actions.
} 
We consider the following two cases: (i) symmetric collusion and (ii) asymmetric collusion.

\subsection{Symmetric collusion}

Throughout this section we use the following assumption.

Assumption 2 (Symmetric Collusion) $\Lambda=\frac{1}{n} \sum_{j=1}^{n} \lambda_{i, j}$, for each $i=1, \ldots, n$.

Assumption 2 states that, on average, the degree of coordination (collusion) among boards is the same for all firms. For $\Lambda=0$ boards choose managerial pay independently ${ }^{8}$, while for $\Lambda=1$ managerial pay is chosen in a perfectly coordinated way to maximize joint firm profits; an increase in $\Lambda$ corresponds to an increase in the degree of board collusion.

The following propositions characterize the pay-for-performance sensitivity and the firm value.

Proposition 3 The pay-for-performance sensitivity is $\alpha_{i}=\alpha^{*}=\frac{x-\sqrt{x^{2}-4 \Lambda(1-\Lambda) x}}{2 \Lambda}$, for each $i=$ $1, \ldots, n . \alpha^{*}$ is decreasing in $x$ and $\Lambda$.

Proposition $4 S_{i}=S$ for each $i$, where $S$ is increasing in $\Lambda$ with $S>S^{I}$ for each $\Lambda>0$.

According to Proposition 3 board of director collusion reduces the pay-for-performance sensitivity, thereby weakening the degree of competition among firms. The strength of the competition-for-demand effect is decreasing in $\Lambda$. In particular, the stronger the board of director collusion is (that is, the larger $\Lambda$ is), the lower the pay-for-performance sensitivity $\alpha^{\star}$, the larger the average price level ${ }^{9}$ and the larger the firm value (Proposition 4). If $\Lambda=0$, then boards choose pay-for-performance sensitivities independently and thus the competition-for-demand effect is strongest. ${ }^{10}$ If $\Lambda=1$, then boards choose pay-for-performance sensitivities in a perfectly coordinated way and thus they anticipate that in the equilibrium a larger $\alpha$ does not lead, on average, to a larger market share and to larger firm profits and thus they do not compete for additional demand through incentive provision (that is, $\alpha^{\star}=0$ ).

The pay-for-performance sensitivity depends positively on the strength of PMC: the lower $x$ is, that is, the larger $n$ and/or $m$ or the lower $t$ is, the greater the pay-for-performance sensitivity. The intuition for this result is as follows. As long as $\Lambda<1$, a reduction in $x$ (i.e. a strengthening in PMC)

\footnotetext{
${ }^{8}$ Note that in this case firms take price expectations as given.

${ }^{9}$ In the symmetric equilibrium the average equilibrium price level is $E(p)=c+\frac{\frac{1}{2} x-\alpha^{\star}}{k} \frac{m}{n}$. Since $\alpha^{\star}$ is decreasing in $t$ and $\Lambda$ and increasing in $n$ and $m$, it follows that $E(p)$ is decreasing in $n$ and $m$ and increasing in $t$ and $\Lambda$.

${ }^{10}$ For $\Lambda=0$ the results in Proposition 2 are obtained.
} 
increases marginal costs and marginal gains of incentive provision. Marginal gains increase more than marginal costs and consequently it is optimal to increase the pay-for-performance sensitivity. ${ }^{11}$

Note that in the present model managerial effort depends not only on the firm's demand ${ }^{12}$ (see, for example, Raith, 2003 and Vives, 2008), but also on the pay-for-performance sensitivity $\alpha_{i}$.

Remark 1 As long as $\Lambda<1$, managerial effort in the symmetric equilibrium $\left(e_{i}^{\star}=\alpha^{\star} \frac{m}{k n}\right)$ is decreasing in $n, t$ and $\Lambda$ and increasing in $m$.

An increase in $n$ reduces the demand of firm $i$ and thus reduces the manager's incentives to cut costs; this negative stimulus is partially countered by a stronger pay-for-performance sensitivity. An increase in market size increases demand of firm $i$ and hence the manager's incentives to cut costs; moreover, it leads to a greater pay-for-performance sensitivity, which further increases managerial effort. A change in $t$ leads to a business stealing effect ${ }^{13}$, a size effect ${ }^{14}$ and to a competition-fordemand effect. Akin to Raith (2003), the former two effects cancel each other, and thus the presence of the third effect leads to a positive relationship between product substitutability and managerial effort. Stronger board collusion leads to a lower competition-for-demand effect and hence to a lower pay-for-performance sensitivity and to lower managerial effort.

\section{$4.2 \quad$ Asymmetric collusion}

In this section we assume that boards can be divided into two groups, group $E$, the corporate elite, and group $D$, the corporate dregs. The former group consists of $n_{E}$ strongly coordinated boards, while the latter one consists of $n_{D}$ weakly coordinated boards, where $\mu_{D}=\frac{n_{D}}{n}, \mu_{E}=\frac{n_{E}}{n}$ and $\mu_{E}+\mu_{D}=1$. We consider two cases. In the first case board coordination between the two groups is negligible, while in the second case it is non-negligible. To keep the model analytically tractable we assume that the

\footnotetext{
${ }^{11}$ The firm value can be written as $S_{i}=E\left(\pi_{i}\right)-\frac{1}{2} k e_{i}^{2}$; after substituting the expressions for $E\left(\pi_{i}\right)$ and $e_{i}$ derived in the proof of Proposition 1, one can write $S_{i} \simeq x \frac{1}{\left(\frac{1}{n} \sum_{j=1}^{n} \frac{x-\alpha_{i}}{x-\alpha_{j}^{e}}\right)^{2}}-\alpha_{i}^{2} \frac{1}{\left(\frac{1}{n} \sum_{j=1}^{n} \frac{x-\alpha_{i}}{x-\alpha_{j}^{e}}\right)^{2}}$. Taking the derivative of $S_{i}$ with respect to $\alpha_{i}$ we obtain $\frac{\partial S_{i}}{\partial \alpha_{i}} \simeq M G-M C$, where $M G=\frac{\partial}{\partial \alpha_{i}} x \frac{1}{\left(\frac{1}{n} \sum_{j=1}^{n} \frac{x-\alpha_{i}}{x-\alpha_{j}^{e}}\right)^{2}}$ are marginal gains and $M C=\frac{\partial}{\partial \alpha_{i}} \alpha_{i}^{2} \frac{1}{\left(\frac{1}{n} \sum_{j=1}^{n} \frac{x-\alpha_{i}}{x-\alpha_{j}^{e}}\right)^{2}}$ are marginal costs. In the symmetric equilibrium, the marginal increase in firm profits is $M G=\frac{x}{x-\alpha^{\star}}(1-\Lambda)$, and the marginal increase in costs due to the manager's disutility of effort is $M C=\alpha^{\star}+$ $\frac{\alpha^{\star 2}}{x-\alpha^{\star}}(1-\Lambda)$.

${ }^{12}$ In the symmetric equilibrium, firm demand is $d_{i}=\frac{m}{n}$.

${ }^{13}$ The lower $t$ is, the more elastic demand becomes, that is, price reductions lead to larger demand increases and hence to greater incentives to cut costs.

${ }^{14} \mathrm{~A}$ lower $t$ reduces the average price level. As an optimal response, the manager of firm $i$ reduces the product's price, thereby reducing the product's demand $\left(d_{i}\right)$. Since the value of cost reductions depends positively on the firm's demand, this reduces the incentives to cut costs.
} 
average degree of coordination within a given group and with boards belonging to the other group is the same for all members.

Assumption 3 (i) $\Lambda_{E}^{W G}=\frac{1}{n_{E}} \sum_{j \in E} \lambda_{i, j}$ and $\Lambda_{E}^{B G}=\frac{1}{n_{D}} \sum_{j \in D} \lambda_{i, j}$ for each $i \in E$; (ii) $\Lambda_{D}^{W G}=$ $\frac{1}{n_{D}} \sum_{j \in D} \lambda_{i, j}$ and $\Lambda_{D}^{B G}=\frac{1}{n_{E}} \sum_{j \in E} \lambda_{i, j}$ for each $i \in D$.

In the next Lemma we characterize between-group coordination.

Lemma 1 Given Assumption 3 and that $\lambda_{i, j}=\lambda_{j, i}$ for each $i, j=1, \ldots, n$, it follows that $\Lambda_{E}^{B G}=$ $\Lambda_{D}^{B G}=\Lambda^{B G}$

The assumption that coordination with boards belonging to the other group is the same for all members of a group together with the assumption that $\lambda_{i, j}=\lambda_{j, i}$ yields a symmetry in the degree of between-group collusion.

$\Lambda_{E}^{W G}, \Lambda_{D}^{W G}$ and $\Lambda^{B G}$ represent the average degree of board coordination among the corporate elite, the corporate dregs and the degree of between-group coordination, respectively. Throughout the remaining section we use one of the following two assumptions.

Assumption 4 (Asymmetric collusion I) $\Lambda_{E}^{W G}>\Lambda_{D}^{W G} \approx 0$ and $\Lambda^{B G}=0$.

Assumption 5 (Asymmetric collusion II) $\Lambda_{E}^{W G}>\Lambda^{B G}>\Lambda_{D}^{W G} \approx 0$ where $\Lambda^{B G}<\min \left\{\frac{9}{16}, \frac{\mu_{E}}{1+\mu_{E}} \Lambda_{E}^{W G}\right\}$

Assumption $\Lambda_{E}^{W G}>\Lambda_{D}^{W G} \approx 0$ implies that board coordination is strong in group $E$ and weak in group $D$. In Assumption 4 we exclude between-group coordination. Assumption 5 states that betweengroup collusion is weaker than collusion among members of the corporate elite, but is stronger than collusion among members of the corporate dregs. Assumption 4 describes the case of a completely isolated weakly coordinated constellation of firms that co-exists with a strongly coordinated corporate elite, while Assumption 5 portrays a strongly coordinated elite and its weakly coordinated periphery ${ }^{15}$.

$\Lambda_{a}=\frac{1}{n} \sum_{j=1}^{n} \lambda_{i, j}$, for each board $i$ belonging to group $a=E, D$, captures the average degree of coordination between a board belonging group $a$ and all other boards, and is consequently a proxy for how influential a board belonging to group $a$ is. Note that under Assumption $4, \Lambda_{a}=\mu_{a} \Lambda_{a}^{W G}$ and thus $\Lambda_{a}$ depends on the degree of within-group board collusion as well as on the group's size. Under Assumption $5, \Lambda_{a}=\mu_{a} \Lambda_{a}^{W G}+\mu_{b} \Lambda^{B G}$ and thus $\Lambda_{a}$ is a weighted average of the degree of within-group and between-group collusion.

\footnotetext{
${ }^{15}$ Note that the analysis could easily be extended to include completely isolated firms, that is, firms in which managerial incentive provision does not influence and is not influenced by incentive provision in other firms, since for such firms complete delegation is optimal.
} 
We are interested in how managerial pay-for-performance sensitivities vary if the degree of withingroup and between-group collusion increases, if the group's size increases ${ }^{16}$, and if PMC weakens.

Proposition 5 Under Assumption 4, the pay-for-performance sensitivity is $\alpha_{i}^{\star}=\alpha_{E}^{\star}<1$ for each $i \in E$ and $\alpha_{i}^{\star}=\alpha_{D}^{\star}<1$ for each $i \in D$, where (i) $\alpha_{E}^{\star} \lessgtr \alpha_{D}^{\star}$ if $\Lambda_{E} \gtrless \Lambda_{D}$; (ii) $\frac{\partial \alpha_{a}^{\star}}{\partial \Lambda_{a}^{W G}}<0$ and $\frac{\partial \alpha_{a}^{\star}}{\partial \mu_{a}}<0$; (iii) $\frac{\partial \alpha_{a}^{\star}}{\partial \Lambda_{b}^{W G}}<0$; (iv) $\frac{\partial \alpha_{a}^{\star}}{\partial x}<0$, for each $a \neq b=E, D$.

Board collusion leads to a lower pay-for-performance sensitivity. The stronger collusion among members of a group is and/or the larger a group is, the weaker the competition-for-demand effect and hence the lower the pay-for-performance sensitivity. Proposition 5 states that managers of firms whose boards are more influential have a lower pay-for-performance sensitivity. The reason is that these boards internalize more the effect of an increase in $\alpha$ on competition. Note that since the board's influence depends not only on the degree of (within-group) board collusion, but also on the group's size, it may happen that members of group $E$ are less influential than members of group $D$ if group $E$ is sufficiently small. Part (iii) of the proposition states that the stronger board collusion in one group is, the lower the pay-for-performance sensitivity in firms belonging to the other group. A lower pay-for-performance sensitivity in firms belonging to group $b$ leads to a larger residual demand for firms belonging to group $a$ and hence leads to weaker within-group competition (i.e. lower payfor-performance sensitivity $\alpha_{a}$ ). Proposition 5 confirms that the pay-for-performance sensitivity is increasing in the strength of PMC.

Proposition 6 Under Assumption 4 the following results hold: (i) if $\Lambda_{E} \gtrless \Lambda_{D}$, then $S_{E} \lessgtr S_{D}$, where $\min \left\{S_{E}, S_{D}\right\}>S^{I}$, with $\frac{\partial S_{a}}{\partial \Lambda_{a}^{W G}}>0$ and $\frac{\partial S_{a}}{\partial \Lambda_{b}^{W G}}>0$, for $a \neq b=E, D$; (ii) if $\Lambda_{E}>\Lambda_{D}$, then $S_{E}$ and $S_{D}$ are increasing in $\mu_{E}$.

Collusion increases firm profits of both groups, but those firms whose boards are less influential benefit more than those whose boards are more influential. The reason for this result is that managers of firms belonging to the former group have, in equilibrium, a higher pay-for-performance sensitivity and therefore stronger incentives to cut costs. As a consequence, expected demand and firm profits in these firms are larger. If the corporate elite is relatively more influential and members of group $D$ are sufficiently uncoordinated (i.e. $\Lambda_{D}^{W G} \approx 0$ ), then increasing $\mu_{E}$ increases profits of both groups. Thus, both groups benefit from the expansion of the corporate elite, but this comes at the cost of those joining the corporate elite, whose firm value declines.

\footnotetext{
${ }^{16}$ We assume that $\mu_{a}, \Lambda_{a}^{W G}$ and $\Lambda^{B G}$ are independent variables.
} 
Proposition 7 Under Assumption 5, the pay-for-performance sensitivity is $\alpha_{i}^{\star}=\alpha_{E}^{\star}<1$ for each $i \in E$ and $\alpha_{i}^{\star}=\alpha_{D}^{\star}<1$ for each $i \in D$, where (i) $\alpha_{E}^{\star}<\alpha_{D}^{\star}$; (ii) $\frac{\partial \alpha_{a}^{\star}}{\partial \Lambda_{a}^{W G}}<0, a=E, D$; (iii) $\frac{\partial \alpha_{E}^{\star}}{\partial \Lambda_{D}^{W G}}<0$, $\frac{\partial \alpha_{E}^{\star}}{\partial \Lambda^{B G}}<0, \frac{\partial \alpha_{D}^{\star}}{\partial \Lambda_{E}^{W G}}>0$ and $\frac{\partial \alpha_{D}^{\star}}{\partial \Lambda^{B G}}$ has an ambiguous sign; (iv) for $\frac{9}{16} \Lambda_{E}^{W G}>\Lambda^{B G}>\frac{16}{9} \Lambda_{D}^{W G}, \frac{\partial \alpha_{E}^{\star}}{\partial \mu_{E}}<0$ while the sign of $\frac{\partial \alpha_{D}^{\star}}{\partial \mu_{D}}$ is ambiguous; (v) for small values of $\Lambda^{B G}, \frac{\partial \alpha_{a}^{\star}}{\partial x}<0, a=E, D$.

Assumption 5 (iii) implies that boards belonging to group $E$ are more influential than those belonging to group $D$ (i.e. $\Lambda_{E}>\Lambda_{D}$ ) and consequently the pay-for-performance sensitivity is lower in firms belonging to the former group. An increase in $\Lambda_{a}^{W G}$ reduces the competition through incentive provision and thus leads to a lower pay-for-performance sensitivity $\alpha_{a}^{\star}$. Proposition 7 states that $\alpha_{D}^{\star}$ is increasing in $\Lambda_{E}^{W G}$, while $\alpha_{E}^{\star}$ is decreasing in $\Lambda_{D}^{W G}$. The reason is as follows. Consider an increase in $\Lambda_{b}^{W G}$, which leads to a reduction in $\alpha_{b}^{\star}$. Since between-group coordination becomes the more important the stronger the other group competes for market share ${ }^{17}$, if coodination occurs only between the two groups, then the optimal response to a reduction in $\alpha_{b}^{\star}$ is to increase $\alpha_{a}$. On the other side, if coordination occurs only within groups, then, as described above ${ }^{18}$, a lower $\alpha_{b}^{\star}$ by increasing the residual demand of group $a$ weakens competition among its members. As a consequence, the overall effect of $\alpha_{b}$ on $\alpha_{a}$ depends on the relative strength of between-group collusion. Given Assumption 5 , for boards belonging to group $E$, between-group collusion is relatively weak and thus a reduction in $\alpha_{D}^{\star}$ leads to a reduction in $\alpha_{E}^{\star}$, while for boards belonging to group $D$, between-group collusion is relatively strong and therefore a reduction in $\alpha_{E}^{\star}$ leads to an increase in $\alpha_{D}^{\star}$. An increase in the size of group $E$ reduces $\alpha_{E}^{\star}$ and has a negligible effect on $\alpha_{D}^{\star}$ if $\Lambda_{D}^{W G}$ and $\Lambda^{B G}$ are small. An increase in the degree of PMC increases the pay-for-performance sensitivity.

Proposition 8 Under Assumption 5 the following results hold: (i) $S_{D}>S_{E}>S^{I}$; (ii) $S_{E}$ is increasing in $\Lambda_{E}^{W G}$ for small values of $\Lambda_{E}^{W G}$ and decreasing in $\Lambda_{E}^{W G}$ for large values of $\Lambda_{E}^{W G} ; S_{D}$ is increasing in $\Lambda_{D}^{W G}$; (iii) $S_{E}$ is increasing in $\Lambda_{D}^{W G}$ and, for small values of $\Lambda^{B G}$, increasing in $\Lambda^{B G}$; for small values of $\Lambda^{B G}, S_{D}$ is increasing in $\Lambda_{E}^{W G}$ and $\Lambda^{B G}$; (iv) for $\frac{9}{16} \Lambda_{E}^{W G}>\Lambda^{B G}>\frac{16}{9} \Lambda_{D}^{W G}$ and for small values of $\Lambda_{D}^{B G}, S_{E}$ and $S_{D}$ are increasing in $\mu_{E}$.

Since boards belonging to group $E$ are more influential than those belonging to group $D$, the payfor-performance sensitivity in the former group of firms is lower and consequently the firm value is lower than in the latter one. The intuition is the same as in Proposition 5. The effect of an increase in $\Lambda_{E}^{W G}$ on $S_{E}$ depends on the value of $\Lambda_{E}^{W G}$. The reason is the following. Because of the competition-for-demand

\footnotetext{
${ }^{17}$ In other words, the impact of between-group collusion on firm values is increasing in $\alpha_{b}$.

${ }^{18}$ See Proposition 5 (iii).
} 
effect, $S_{E}$ is decreasing in $\alpha_{E}^{\star}$ and $\alpha_{D}^{\star}$. Consequently, an increase in $\Lambda_{E}^{W G}$, by increasing $\alpha_{D}^{\star}$, affects $S_{E}$ negatively and, by decreasing $\alpha_{E}^{\star}$, affects $S_{E}$ positively (see Proposition 7). Since the latter effect is negligible for values of $\Lambda_{E}^{W G}$ close to one ${ }^{19}$, the negative effect dominates the positive one and therefore an increase in $\Lambda_{E}^{W G}$ reduces $S_{E}$. For small values of $\Lambda_{E}^{W G}$ the negative effect is very small (in particular, the change in $\alpha_{D}^{\star}$ is very small) and it is therefore dominated by the positive effect, and consequently an increase in $\Lambda_{E}^{W G}$ increases $S_{E}$. Thus, an inverted-U relationship between the shareholder value of firms belonging to the corporate elite and the degree of collusion among boards belonging to this elite exists. It follows that perfect board coordination among members of the corporate elite is never optimal since gains from collusion due to weaker competition among group members are outweighed by losses due to stronger competition from members belonging to the corporate dregs. An increase in $\Lambda_{D}^{W G}$, by decreasing both $\alpha_{E}^{\star}$ and $\alpha_{D}^{\star}$, increases $S_{E}$ and $S_{D}$. An increase in $\Lambda_{E}^{W G}$ leads to a reduction in $\alpha_{E}^{\star}$, which positively affects $S_{D}$, and to an increase in $\alpha_{D}^{\star}$, which negatively affects $S_{D}$. If $\Lambda_{D}^{W G}$ and $\Lambda^{B G}$ are small, then the latter effect is negligible and therefore the relationship is positive. Moreover, if $\Lambda_{D}^{W G}$ and $\Lambda^{B G}$ are sufficiently small, then increasing $\Lambda^{B G}$ increases $S_{E}$ and $S_{D}$ and an increase in the size of the corporate elite increases the shareholder value of all firms but the one switching from the corporate dregs to the corporate elite.

\section{Conclusions}

We argued that board of director collusion reduces managerial pay-for-performance sensitivities with the aim to curb competition and to boost firm values. We studied how pay-for-performance sensitivities vary as the degree of board collusion changes. In particular, we found that the more influential a board is, that is, the greater the board's average degree of coordination with all other boards is, the lower the pay-for-performance sensitivity. We also investigated the effect of board collusion on firm values and hence on incentives to collude. We showed that board of director collusion benefits all firms, but those whose boards are more influential gain less. We showed that if boards belonging to the corporate elite are more influential, then increasing its group size increases the shareholder value of all firms but the one joining the corporate elite. We found that increasing the degree of board collusion among members of the corporate elite always increases firm values of the corporate dregs but not necessarily those of the corporate elite. In particular, we evidenced that if board collusion among the two groups is non-negligible, then increasing the degree of collusion among members of the elite leads to an increase

\footnotetext{
${ }^{19}$ To see this note that, because of the envelop theorem, in the limit of $\Lambda_{E}^{W G} \rightarrow 1, \frac{\partial S_{a}}{\partial \alpha_{a}^{\star}} \rightarrow 0$.
} 
in firm value if collusion is weak and to a decrease if collusion is strong. Thus, in general, it is not optimal for the corporate elite to choose managerial pay that maximizes joint profits.

\section{References}

[1] Aggarwal, R.K. and A.A. Samwick, 1999. Executive Compensation, Strategic Competition, and Relative Performance Evaluation: Theory and Evidence. Journal of Finance, 54, 1999-2043.

[2] Barnea, A. and I. Guedj, 2009. Director Networks. Working paper.

[3] Bizjak, J., M. Lemmon and R. Whitby, 2009. Option Backdating and Board Interlocks. Review of Financial Studies, 22, 4821 - 4847.

[4] Burt, R. S., 1983. Corporate Profits and Co-optation: Networks of Market Constraints and Directorate Ties in the American Economy. New York: Academic Press.

[5] Chiu, P.-C., S.H. Teoh and F. Tian, 2010. Board Interlocks and Earnings Management Contagion. Working paper.

[6] Conyon, M.J. and M.R. Muldoon, 2006. The Small World of Corporate Boards. Journal of Business Finance and Accounting, 33, 1321 - 1343.

[7] Cuñat, V. and M. Guadalupe, 2005. How Does Product Market Competition Shape Incentive Contracts. Journal of the European Economic Association, 3, 1058 - 1082.

[8] Cuñat, V. and M. Guadalupe, 2009a. Executive Compensation and Competition in the Banking and Financial Sectors. Journal of Banking \& Finance, 33, 439 - 474.

[9] Cuñat, V. and M. Guadalupe, 2009b. Globalization and the Provision of Incentives Inside the Firm: the Effect of Foreign Competition. Journal of Labor Economics, 27, 179 - 212.

[10] Davis, G., 1991. Agents without Principles? The Spread of the Poison Pill through the Intercorporate Network. Administrative Science Quarterly, 36, 583 - 613.

[11] Davis, G. and H. Greve, 1997. Corporate Elite Networks and Governance Changes in the 1980s. American Journal of Sociology, 103, 1 - 37. 
[12] Davis, G., M. Yoo and W.E. Baker, 2003. The Small World of the American Corporate Elite, 1982-2001. Strategic Organization, 1, 301 - 326.

[13] Denicolò, V. and P. Zanchettin, 2010. Competition, Market Selection and Growth. Economic Journal, 120, 761 - 785 .

[14] Dooley, P. C., 1969. The Interlocking Directorate. American Economic Review, 59, 314 323.

[15] Fershtman, C., 1985. Internal Organizations and Managerial Incentives as Strategic Variables in Competitive Environment. International Journal of Industrial Organization, 3, $245-253$.

[16] Fershtman, C. and K.L. Judd, 1987. Equilibrium Incentives in Oligopoly. American Economic Review, 77, 927 - 940.

[17] Fershtman, C., Judd K.L. and E. Kalai, 1991. Strategic Delegation and Cooperation. International Economic Review, 32, 551-559.

[18] Fich, E. M. and L. J. White, 2003. CEO Compensation and Turnover: The Effects of Mutually Interlocked Boards. Wake Forest Law Review, 38, 935 - 959.

[19] Hallock, K. F., 1997. Reciprocally Interlocking Boards of Directors and Executive Compensation. Journal of Financial and Quantitative Analysis, 32, 331 - 344.

[20] Hansen R.G. and J.R. Lott, 1996. Externalities and Corporate Objectives in a World with Diversified Shareholder/Consumers. Journal of Financial and Quantitative Analysis, 31, $43-68$.

[21] Haunschild, P., 1993. Interorganizational Imitation: The Impact of Interlocks on Corporate Acquisition Activity. Administrative Science Quarterly, 38, 564 - 92.

[22] Haunschild, P. and C. Beckman, 1998. When Do Interlocks Matter? Alternate Sources of Information and Interlock Influence. Administrative Science Quarterly, 43, 815 - 44.

[23] Joh, S.W., 1999. Strategic managerial incentive compensation in Japan: Relative performance evaluation and product market collusion. The Review of Economic and Statistics, 812, 303-313. 
[24] Karuna, C., 2007. Industry Product Market Competition and Managerial Incentives. Journal of Accounting and Economics, 43, 275 - 297.

[25] Kedia, S., 2006. Estimating product market competition: Methodology and application. Journal of Banking 83 Finance, 30, 875 - 894.

[26] Koenig, T., R. Gogel and J. Sonquist, 1979. Model of the Significance of Interlocking Corporate Directorates. American Journal of Economics and Sociology, 38, 173 - 186.

[27] Kuhnen, C.M., 2009. Business Networks, Corporate Governance and Contracting in the Mutual Fund Industry. Journal of Finance, 64, 2185 - 2220.

[28] Larcker, D., S.A. Richardson, A. J. Seary, and I. Tuna, 2005. Back Door Links between Directors and Executive Compensation. Working paper.

[29] Murphy, K.J., 1999. Executive Compensation. In Handbook of Labor Economics, Volume IIIb. Orley Ashenfelter and David Card, eds. Amsterdam: North Holland, 2485 - 2563.

[30] Raheja, C.G., 2005. Determinants of Board Size and Composition: A Theory of Corporate Boards. Journal of Financial and Quantitative Anlaysis, 40, 283 - 306.

[31] Raith, M., 2003. Competition, Risk, and Managerial Incentives. American Economic Review, 93, $1425-1436$.

[32] Renneboog, L. and Y. Zhao, 2011. US Knows Us in the UK: On Director Networks and CEO Compensation. TILEC Discussion Paper No. 2011-014.

[33] Salop, S.C., 1979. Monopolistic Competition with Outside Goods. The Bell Journal of Economics, 10, 141-156.

[34] Schmidt, K.M., 1997. Managerial Incentives and Product Market Competition. Review of Economic Studies, 64, 191 - 213.

[35] Sklivas, S.D., 1987. The Strategic Choice of Managerial Incentives. RAND Journal of Economics, 18, 452-458.

[36] Spagnolo, G., 2000. Stock-Related Compensation and Product-Market Competition. RAND Journal of Economics, 31, 22-42. 
[37] Stuart, T. and S. Yim, 2010. Board Interlocks and the Propensity to be Targeted in Private Equity Transactions. Journal of Financial Economics, 97, 1974 - 189.

[38] Vickers, J., 1985. Delegation and the Theory of the Firm. Economic Journal, 95, 138-147.

[39] Vives, X., 2008. Innovation and Competitive Pressure. Journal of Industrial Economics, $56,419-469$.

\section{Appendix}

Proof of Proposition 1. The model is solved backwards. Consider first the stage in which prices are chosen. Each firm competes with two neighbors. The utility function of a consumer positioned at $x$ and buying from producer $i$ positioned at $z_{i}$ is $V_{i}(x)=s-p_{i}-t\left(x-z_{i}\right)^{2}$. A consumer positioned at $x_{i^{+}}$is indifferent between buying from producer $i$ or $i+1$ if $V_{i}\left(x_{i^{+}}\right)=V_{i+1}\left(x_{i^{+}}\right) .{ }^{20}$ Since what matters to consumers (apart from prices $p_{i}$ and $p_{i+1}$ ) is the distance between producer $i$ and $i+1$, which is $\frac{1}{n}$, we can, without loss of generality, position producer $i$ in 0 and $i+1$ in $\frac{1}{n}$. Consequently, for given prices $p_{i}$ and $p_{i+1}$, the marginal consumer on the right-hand-side market of firm $i$ is implicitly defined by $s-p_{i}-t\left(x_{i^{+}}\right)^{2}=s-p_{i+1}-t\left(\frac{1}{n}-x_{i^{+}}\right)^{2}$. Since the manager of firm $i$ does not know the production costs of neighboring firms and therefore their prices, firm $i$ expects its neighbors to charge the expected price $E\left(p_{i_{+}}\right)$, where $E\left(p_{i_{+}}\right)$will be calculated in a consistent way. Hence, the expected position of the marginal consumer on the right-hand-side market is

$$
E\left(x_{i_{+}}\right)=\frac{E\left(p_{i_{+}}\right)-p_{i}+t\left(\frac{1}{n}\right)^{2}}{2 t \frac{1}{n}} .
$$

The expected position of the marginal consumer on the left-hand-side market can be obtained in a similar way. Given a mass $m$ of consumers, that firm $i$ operates on the left-hand-side and the righthand-side market we have that the expected demand of firm $i$ is

$$
E\left(d_{i}\right)=m E\left(x_{i_{+}}+x_{i_{-}}\right)=m\left(\frac{E\left(p_{i}\right)-p_{i}}{t \frac{1}{n}}+\frac{1}{n}\right)
$$

\footnotetext{
${ }^{20}$ Indices $i+1$ and $i-1$ indicate the nearest neighbor of firm $i$ on the right-hand-side and left-hand-side market, respectively.
} 
where $E\left(p_{i}\right)=\frac{1}{2}\left[E\left(p_{i_{-}}\right)+E\left(p_{i_{+}}\right)\right]$. Given the production cost $c_{i}$, which is known at this stage, effort $e_{i}$ and the expected price $E\left(p_{i}\right)$, the pricing policy chosen by the manager of firm $i$ is

$$
p_{i}=\frac{E\left(p_{i}\right)+c+\varepsilon_{i}-e_{i}+t\left(\frac{1}{n}\right)^{2}}{2} .
$$

We next calculate managerial effort, which depends on the manager's utility function and on the incentive contract. Using (5) and (4), and since the manager does not know the realization of $\varepsilon_{i}$, the manager's expected utility is

$$
E\left[U\left(W_{i}\right)\right]=(1-\alpha) w_{i}+\alpha_{i} \frac{n m}{4 t}\left\{\left[E\left(p_{i}\right)-c+e_{i}+\frac{t}{n^{2}}\right]^{2}+\sigma^{2}\right\}-\frac{1}{2} k e_{i}^{2} .
$$

First order condition ${ }^{21}$ (FOC) yields optimal effort level $e_{i}=\frac{\alpha_{i}}{x-\alpha_{i}}\left[E\left(p_{i}\right)-c-\varepsilon_{i}+\frac{t}{n}\right]$, where $x=$ $2 t k \frac{1}{n m}$. We solve for the expected price level. Given (5), we have that

$$
E\left(p_{i}\right)=c-E\left(e_{i}\right)+\frac{t}{n^{2}},
$$

where $E\left(e_{i}\right)=\frac{1}{2}\left[E\left(e_{i_{+}}\right)+E\left(e_{i_{-}}\right)\right]$and

$$
E\left(e_{i}\right)=\frac{1}{2}\left\{\frac{E\left(\alpha_{i_{+}}\right)}{x-E\left(\alpha_{i_{+}}\right)}\left[E\left(p_{i_{+}}\right)-c+\frac{t}{n^{2}}\right]+\frac{E\left(\alpha_{i_{-}}\right)}{x-E\left(\alpha_{i_{-}}\right)}\left[E\left(p_{i_{-}}\right)-c+\frac{t}{n^{2}}\right]\right\} .
$$

Using (7), the average expected price level is

$E(p)=\frac{1}{n} \sum_{i=1}^{n} E\left(p_{i}\right)=c+\frac{t}{n^{2}}-\frac{1}{2} \frac{1}{n} \sum_{i=1}^{n}\left\{\frac{E\left(\alpha_{i_{+}}\right)}{x-E\left(\alpha_{i_{+}}\right)}\left[E\left(p_{i_{+}}\right)-c+\frac{t}{n^{2}}\right]+\frac{E\left(\alpha_{i_{-}}\right)}{x-E\left(\alpha_{i_{-}}\right)}\left[E\left(p_{i_{-}}\right)-c+\frac{t}{n^{2}}\right]\right\}$.

We assume that board directors are unable to disentangle the effects of all direct and indirect board ties and we therefore focus on a Bayesian equilibrium, where $E\left(p_{i}\right)=E(p)$ for each $i$. After simplifying terms the expected price level reads

$$
E(p)=c+\frac{t}{n^{2}} \frac{1-\frac{1}{n} \sum_{j=1}^{n} \frac{E\left(\alpha_{j}\right)}{x-E\left(\alpha_{j}\right)}}{\frac{1}{n} \sum_{j=1}^{n} \frac{x}{x-E\left(\alpha_{j}\right)}}
$$

\footnotetext{
${ }^{21}$ Assumption 1 (i) guarantees that the second order condition is always satisfied.
} 
and hence effort (1) and expected demand (2) can be obtained. Expected profits are

$$
E\left(\pi_{i}\right)=\frac{1}{2} \frac{k}{x}\left[\left(\frac{2 \frac{t}{n^{2}}}{\frac{1}{n} \sum_{j=1}^{n} \frac{x-\alpha_{i}}{x-E\left(\alpha_{j}\right)}}\right)^{2}+\sigma^{2}\right]
$$

Using (6), the manager's binding participation constraint reads

$$
E\left(U\left(W_{i}\right)\right)=\left(1-\alpha_{i}\right) w_{i}+\alpha_{i} \frac{1}{2} \frac{k}{x}\left[\left(\frac{2 \frac{t}{n^{2}}}{\frac{1}{n} \sum_{j=1}^{n} \frac{x-\alpha_{i}}{x-E\left(\alpha_{j}\right)}}\right)^{2}+\sigma^{2}\right]-\frac{1}{2} \frac{k}{x^{2}} \alpha_{i}^{2}\left(\frac{2 \frac{t}{n^{2}}}{\frac{1}{n} \sum_{j=1}^{n} \frac{x-\alpha_{i}}{x-E\left(\alpha_{j}\right)}}\right)^{2}=0 .
$$

Substituting $w_{i}$, obtained from the binding participation constraint (9), into the expression for the firm value we get, after simplifying terms, (3).

Proof of Proposition 2. If pay-for-performance sensitivities are chosen independently, then $\alpha_{i}$ does not affect $E\left(\alpha_{j}\right)$, for $i, j=1, \ldots, n$. Hence, maximizing $S_{i}$ with respect to $\alpha_{i}$ yields the result stated in the proposition.

Proof of Proposition 3. The first order condition for $\alpha^{\star}$ is

$$
\frac{1-\alpha_{i}}{x-\alpha_{i}}-\frac{x-\alpha_{i}^{2}}{1+\frac{1}{n} \sum_{j=1}^{n} \frac{E\left(\alpha_{j}\right)}{x-E\left(\alpha_{j}\right)}} \frac{1}{n} \sum_{j=1}^{n} \frac{\lambda_{i, j}}{\left[x-E\left(\alpha_{j}\right)\right]^{2}}=0 .
$$

Using Assumption 2, and imposing the symmetry condition $\alpha_{i}=\alpha,(10)$ can be rewritten $\operatorname{as}^{22}$ $x(1-\alpha-\Lambda)+\alpha^{2} \Lambda=0$. Hence, the result stated in the proposition follows.

Proof of Proposition 4. In the symmetric equilibrium $S_{i}=S=\frac{1}{4 t} n m \sigma^{2}+\left(x-\alpha^{\star 2}\right) \frac{1}{2 k}\left(\frac{m}{n}\right)^{2}$, which in view of Proposition 3 is increasing in $\Lambda$.

Proof of Remark 1. Since $\alpha^{\star}$ is increasing in $m$ and decreasing in $t$ and $\Lambda$ it follows that $e_{i}^{\star}$ is increasing in $m$ and decreasing in $t$ and $\Lambda$. To see that $e_{i}^{\star}$ is decreasing in $n$ take the derivative with respect to $n$. After rearranging terms one obtains that $\frac{\partial e_{i}^{\star}}{\partial n}<0$ if $9 \Lambda(1-\Lambda)<2 x$, which, since by assumption $x>4$, is always true.

Proof of Lemma 1. Since $\lambda_{i, j}=\lambda_{j, i}$ for each $i, j$, we can write $\lambda_{i, j}=n_{E} \Lambda_{D}^{B G}-\left(\sum_{u \in E-\{i\}} \lambda_{j, u}\right)$,

\footnotetext{
${ }^{22}$ One can show that the second order condition is always satisfied.
} 
for each $i \in E$. Substituting this expression into the formula $\Lambda_{E}^{B G}=\frac{1}{n_{D}} \sum_{j \in D} \lambda_{i, j}$ we obtain

$$
\Lambda_{E}^{B G}=\frac{1}{n_{D}}\left[n_{D} n_{E} \Lambda_{D}^{B G}-\sum_{j \in D} \sum_{u \in E-\{i\}} \lambda_{j, u}\right]
$$

which, remembering that $\lambda_{j, u}=\lambda_{u, j}$, after rearranging terms reads

$$
\Lambda_{E}^{B G}=\frac{1}{n_{D}}\left[n_{D} n_{E} \Lambda_{D}^{B G}-\left(n_{E}-1\right) n_{D} \Lambda_{E}^{B G}\right]
$$

and thus establishes the result.

Proof of Proposition 5. First order condition (10) can be written as follows

$$
\chi^{a}\left(\alpha_{E}, \alpha_{D}\right)=1-\alpha_{a}-\frac{x-\alpha_{a}^{2}}{x-\alpha_{a}} \frac{1}{1+\mu_{E} \frac{\alpha_{E}}{x-\alpha_{E}}+\mu_{D} \frac{\alpha_{D}}{x-\alpha_{D}}} \mu_{a} \Lambda_{a}^{W G}=0,
$$

for $a=E, D$. Using (11) we can write

$$
\frac{1-\alpha_{E}}{1-\alpha_{D}} \frac{x-\alpha_{E}}{x-\alpha_{E}^{2}} \frac{x-\alpha_{D}^{2}}{x-\alpha_{D}}=\frac{\mu_{E} \Lambda_{E}^{W G}}{\mu_{D} \Lambda_{D}^{W G}}
$$

Since $(1-\alpha) \frac{x-\alpha}{x-\alpha^{2}}$ is decreasing in $\alpha$, result (i) follows. Taking the derivatives of $\chi^{a}$ it can be shown that $\chi_{\alpha_{a}}^{a}\left(\alpha_{E}, \alpha_{D}\right)<0$ for each $a=E, D$ and that $\chi_{\alpha_{b}}^{a}\left(\alpha_{E}, \alpha_{D}\right)>0$ for each $a \neq b=E, D$. Taking the total differential with respect to $y$

$$
\begin{gathered}
\chi_{\alpha_{E}}^{E} \frac{\partial \alpha_{E}^{\star}}{\partial y}+\chi_{\alpha_{D}}^{E} \frac{\partial \alpha_{D}^{\star}}{\partial y}+\chi_{y}^{E}=0 \\
\chi_{\alpha_{E}}^{D} \frac{\partial \alpha_{E}^{\star}}{\partial y}+\chi_{\alpha_{D}}^{D} \frac{\partial \alpha_{D}^{\star}}{\partial y}+\chi_{y}^{D}=0,
\end{gathered}
$$

where $y=\Lambda_{E}^{W G}, \Lambda_{D}^{W G}, \mu_{E}$ and $x$. After rearranging terms one obtains

$$
\frac{\partial \alpha_{a}^{\star}}{\partial y}=\frac{\chi_{y}^{b} \chi_{\alpha_{b}}^{a}-\chi_{y}^{a} \chi_{\alpha_{b}}^{b}}{\chi_{\alpha_{a}}^{a} \chi_{\alpha_{b}}^{b}-\chi_{\alpha_{b}}^{a} \chi_{\alpha_{a}}^{b}}
$$

for $a \neq b=E, D$. Given Assumption 4, it follows that $\chi_{\alpha_{E}}^{E} \chi_{\alpha_{D}}^{D}>\chi_{\alpha_{D}}^{E} \chi_{\alpha_{E}}^{D}$. Since $\chi_{\Lambda_{a}^{W G}}^{a}<0$ and $\chi_{\Lambda_{b}^{W G}}^{a}=0$ for each $a \neq b=E, D$ it follows that $\frac{\partial \alpha_{a}^{\star}}{\partial \Lambda_{a}^{W G}}<0$ for $a=E, D$ and $\frac{\partial \alpha_{a}^{\star}}{\partial \Lambda_{b}^{W G}}<0, a \neq b=E, D$. 
To prove that $\frac{\partial \alpha_{a}^{\star}}{\partial \mu_{a}}<0$ we have to show that $\chi_{\mu_{a}}^{b} \chi_{\alpha_{b}}^{a}<\chi_{\mu_{a}}^{a} \chi_{\alpha_{b}}^{b}$, which can be written as

$$
\begin{aligned}
& -\frac{x-\alpha_{b}^{2}}{x-\alpha_{b}} \frac{1}{\left(1+\mu_{E} \frac{\alpha_{E}}{x-\alpha_{E}}+\mu_{D} \frac{\alpha_{D}}{x-\alpha_{D}}\right)^{2}} \Lambda_{b}^{W G}\left\{\left(\frac{\alpha_{b}}{x-\alpha_{b}}-\frac{\alpha_{a}}{x-\alpha_{a}}\right) \mu_{b}-\left[1+\mu_{E} \frac{\alpha_{E}}{x-\alpha_{E}}+\mu_{D} \frac{\alpha_{D}}{x-\alpha_{D}}\right]\right\} \times \\
& \frac{x-\alpha_{a}^{2}}{x-\alpha_{a}} \frac{1}{\left(1+\mu_{E} \frac{\alpha_{E}}{x-\alpha_{E}}+\mu_{D} \frac{\alpha_{D}}{x-\alpha_{D}}\right)^{2}} \mu_{b} \frac{x}{\left(x-\alpha_{b}\right)^{2}} \mu_{a} \Lambda_{a}^{W G}< \\
& \frac{x-\alpha_{a}^{2}}{x-\alpha_{a}} \frac{1}{\left(1+\mu_{E} \frac{\alpha_{E}}{x-\alpha_{E}}+\mu_{D} \frac{\alpha_{D}}{x-\alpha_{D}}\right)^{2}} \Lambda_{a}^{W G}\left\{\left(\frac{\alpha_{a}}{x-\alpha_{a}}-\frac{\alpha_{b}}{x-\alpha_{b}}\right) \mu_{a}-\left[1+\mu_{E} \frac{\alpha_{E}}{x-\alpha_{E}}+\mu_{D} \frac{\alpha_{D}}{x-\alpha_{D}}\right]\right\} \times \\
& \left\{-1-\frac{x\left(1-2 \alpha_{b}\right)+\alpha_{b}^{2}}{\left(x-\alpha_{b}\right)^{2}} \frac{1}{1+\mu_{E} \frac{\alpha_{E}}{x-\alpha_{E}}+\mu_{D} \frac{\alpha_{D}}{x-\alpha_{D}}} \mu_{b} \Lambda_{b}^{W G}+x \frac{x-\alpha_{b}^{2}}{\left(x-\alpha_{b}\right)^{3}} \frac{1}{\left(1+\mu_{E} \frac{\alpha_{E}}{x-\alpha_{E}}+\mu_{D} \frac{\alpha_{D}}{x-\alpha_{D}}\right)^{2}} \mu_{b}^{2} \Lambda_{b}^{W G}\right\}
\end{aligned}
$$

After simplifying terms, the inequality reads

$$
\frac{2 \alpha_{b}}{x-\alpha_{b}} \frac{1}{\left(1+\mu_{E} \frac{\alpha_{E}}{x-\alpha_{E}}+\mu_{D} \frac{\alpha_{D}}{x-\alpha_{D}}\right)} \mu_{b} \Lambda_{b}^{W G}<1
$$

which is always true. Taking the derivative of $\chi^{a}$ with respect to $x$ we obtain

$$
\begin{gathered}
\chi_{x}^{a}\left(\alpha_{E}, \alpha_{D}\right)=\alpha_{a} \frac{1-\alpha_{a}}{\left(x-\alpha_{a}\right)^{2}} \frac{1}{1+\mu_{E} \frac{\alpha_{E}}{x-\alpha_{E}}+\mu_{D} \frac{\alpha_{D}}{x-\alpha_{D}}} \mu_{a} \Lambda_{a}^{W G}+ \\
-\frac{x-\alpha_{a}^{2}}{x-\alpha_{a}} \frac{1}{\left(1+\mu_{E} \frac{\alpha_{E}}{x-\alpha_{E}}+\mu_{D} \frac{\alpha_{D}}{x-\alpha_{D}}\right)^{2}}\left[\mu_{E} \frac{\alpha_{E}}{\left(x-\alpha_{E}\right)^{2}}+\mu_{D} \frac{\alpha_{D}}{\left(x-\alpha_{D}\right)^{2}}\right] \mu_{a} \Lambda_{a}^{W G}
\end{gathered}
$$

After rearranging terms and substituting the FOC (11) one obtains that $\chi_{x}^{a}\left(\alpha_{E}, \alpha_{D}\right)<0$ if

$$
\alpha_{a} \mu_{a} \Lambda_{a}^{W G}<\mu_{a} \alpha_{a}+\mu_{b} \alpha_{b} \frac{\left(x-\alpha_{a}\right)^{2}}{\left(x-\alpha_{b}\right)^{2}}
$$

which is satisfied for $a \neq b=E, D$ and consequently $\frac{\partial \alpha_{a}^{\star}}{\partial x}<0$, for $a=E, D$.

Proof of Proposition 6. In the asymmetric equilibrium, the shareholder value of firms belonging to group $E$ and $D$ is, respectively,

$$
\begin{aligned}
S_{E} & =\frac{1}{4 t} n m \sigma^{2}+\frac{x-\alpha_{E}^{\star 2}}{\left(x-\alpha_{E}^{\star}\right)^{2}} \frac{1}{2 k}\left(\frac{1}{\mu_{E} \frac{1}{x-\alpha_{E}^{\star}}+\mu_{D} \frac{1}{x-\alpha_{D}^{\star}}} \frac{m}{n}\right)^{2} \\
S_{D} & =\frac{1}{4 t} n m \sigma^{2}+\frac{x-\alpha_{D}^{\star 2}}{\left(x-\alpha_{D}^{\star}\right)^{2}} \frac{1}{2 k}\left(\frac{1}{\mu_{E} \frac{1}{x-\alpha_{E}^{\star}}+\mu_{D} \frac{1}{x-\alpha_{D}^{\star}}} \frac{m}{n}\right)^{2} .
\end{aligned}
$$

We first show that $\frac{\partial S_{a}}{\partial \alpha_{a}^{\star}}<0$, for $a=E, D$. Consider the case $a=E$ (the case $a=D$ is perfectly symmetric), in which 


$$
\frac{\partial S_{E}}{\partial \alpha_{E}^{\star}}=2 \frac{x\left(1-\alpha_{E}^{\star}\right)}{\left(x-\alpha_{E}^{\star}\right)^{3}}\left(\frac{1}{\mu_{E} \frac{1}{x-\alpha_{E}^{\star}}+\mu_{D} \frac{1}{x-\alpha_{D}^{\star}}}\right)^{2}-\frac{x-\alpha_{E}^{\star 2}}{\left(x-\alpha_{E}^{\star}\right)^{2}} 2\left(\frac{1}{\mu_{E} \frac{1}{x-\alpha_{E}^{\star}}+\mu_{D} \frac{1}{x-\alpha_{D}^{\star}}}\right)^{3} \mu_{E} \frac{1}{\left(x-\alpha_{E}^{\star}\right)^{2}} .
$$

Therefore, $\frac{\partial S_{E}}{\partial \alpha_{E}^{\star}} \leq 0$ if

$$
1-\alpha_{E}^{\star}<\frac{x-\alpha_{E}^{\star 2}}{\left(x-\alpha_{E}^{\star}\right)} \frac{1}{x} \frac{1}{\mu_{E} \frac{1}{x-\alpha_{E}^{\star}}+\mu_{D \frac{1}{x-\alpha_{D}^{\star}}}} \mu_{E}
$$

Substituting FOC (11) into the left-hand-side of this expression and simplifying terms, the inequality reads $\Lambda_{E}^{W G} \leq 1$, which is always true. It is easy to see that $\frac{\partial S_{E}}{\partial \alpha_{D}^{\star}}<0$. The total differential of $S_{a}$ with respect to $\Lambda_{a}^{W G}$ is

$$
\frac{d S_{a}}{d \Lambda_{a}^{W G}}=\frac{\partial S_{a}}{\partial \alpha_{a}^{\star}} \frac{\partial \alpha_{a}^{\star}}{\partial \Lambda_{a}^{W G}}+\frac{\partial S_{a}}{\partial \alpha_{b}^{\star}} \frac{\partial \alpha_{b}^{\star}}{\partial \Lambda_{a}^{W G}}
$$

where $a \neq b=E, D$. Since $\frac{\partial S_{a}}{\partial \alpha_{a}^{\star}} \frac{\partial \alpha_{a}^{\star}}{\partial \Lambda_{a}^{W G}} \geq 0$ and $\frac{\partial S_{a}}{\partial \alpha_{b}^{\star}} \frac{\partial \alpha_{b}^{\star}}{\partial \Lambda_{a}^{W G}}>0$ it follows that $\frac{d S_{a}}{d \Lambda_{a}^{W G}}>0$. The total differential of $S_{a}$ with respect to $\Lambda_{b}^{W G}$ is

$$
\frac{d S_{a}}{d \Lambda_{b}^{W G}}=\frac{\partial S_{a}}{\partial \alpha_{a}^{\star}} \frac{\partial \alpha_{a}^{\star}}{\partial \Lambda_{b}^{W G}}+\frac{\partial S_{a}}{\partial \alpha_{b}^{\star}} \frac{\partial \alpha_{b}^{\star}}{\partial \Lambda_{b}^{W G}}
$$

where $a \neq b=E, D$. Since $\frac{\partial S_{a}}{\partial \alpha_{a}^{\star}} \frac{\partial \alpha_{a}^{\star}}{\partial \Lambda_{b}^{W G}} \geq 0$ and $\frac{\partial S_{a}}{\partial \alpha_{b}^{\star}} \frac{\partial \alpha_{b}^{\star}}{\partial \Lambda_{b}^{W G}}>0$ it follows that $\frac{d S_{a}}{d \Lambda_{b}^{W G}}>0$.

Since $\frac{\partial S_{a}}{\partial \alpha_{a}^{\star}}<0$ and $\frac{\partial S_{a}}{\partial \alpha_{b}^{\star}}<0$ for $a, b=E, D$, it follows that $S^{I}<S_{E}$. As long as $\Lambda_{E}^{W G}>0, \alpha_{E}^{\star}<1$ and hence also $S^{I}<S_{D}$. To prove that if $\alpha_{E}^{\star} \lessgtr \alpha_{D}^{\star}$ then $S_{D} \gtrless S_{E}$, it is sufficient to observe that $\frac{x-\alpha^{2}}{(x-\alpha)^{2}}$ is increasing in $\alpha$.

Finally, we consider the effect a change in $\mu_{a}$ has on $S_{a}$. Taking the total differential we obtain

$$
\frac{d S_{a}}{d \mu_{a}}=\frac{\partial S_{a}}{\partial \mu_{a}}+\frac{\partial S_{a}}{\partial \alpha_{a}^{\star}} \frac{\partial \alpha_{a}^{\star}}{\partial \mu_{a}}+\frac{\partial S_{a}}{\partial \alpha_{b}^{\star}} \frac{\partial \alpha_{b}^{\star}}{\partial \mu_{a}}
$$

Note that

$$
\frac{\partial S_{a}}{\partial \mu_{a}}=-\frac{x-\alpha_{a}^{\star} 2}{\left(x-\alpha_{a}^{\star}\right)^{2}} \frac{1}{k}\left(\frac{m}{n}\right)^{2}\left(\frac{1}{\mu_{E} \frac{1}{x-\alpha_{E}^{\star}}+\mu_{D} \frac{1}{x-\alpha_{D}^{\star}}}\right)^{3}\left(\frac{1}{x-\alpha_{a}}-\frac{1}{x-\alpha_{b}}\right) .
$$

It follows that if $\mu_{E} \Lambda_{E}^{W G}>\mu_{D} \Lambda_{D}^{W G}$ (that is, $\alpha_{E}<\alpha_{D}$ ) and $\Lambda_{D}^{W G}$ is sufficiently small, then: (i) $\frac{d S_{E}}{d \mu_{E}}$ is positive, since the first two terms in (18) are positive, while the third term is negligible small; (ii) $\frac{d S_{D}}{d \mu_{D}}$ is negative, since the first and third terms in (18) are negative, while the second term is negligible 
small.

Proof of Proposition 7. First order condition (10) can be written as follows

$$
\Omega^{a}\left(\alpha_{E}, \alpha_{D}\right)=1-\alpha_{a}-\frac{1}{x} \frac{x-\alpha_{a}^{2}}{x-\alpha_{a}} \frac{1}{\mu_{E} \frac{1}{x-\alpha_{E}}+\mu_{D} \frac{1}{x-\alpha_{D}}}\left[\mu_{a} \Lambda_{a}^{W G}+\mu_{b} \Lambda^{B G}\left(\frac{x-\alpha_{a}}{x-\alpha_{b}}\right)^{2}\right]
$$

where $\Omega_{\alpha_{a}}^{a}<0$ for $a=E, D$ and, given Assumption $5, \Omega_{\alpha_{E}}^{D}<0$ and $\Omega_{\alpha_{D}}^{E}>0 .{ }^{23}$ Comparing FOC for firms belonging to group $E$ with those belonging to group $D$ we observe that

$$
\alpha_{E}^{\star} \lessgtr \alpha_{D}^{\star} \Longleftrightarrow(1-\mu) \Lambda_{E}^{W G}+\mu \Lambda^{B G} \gtrless \mu \Lambda_{D}^{W G}+(1-\mu) \Lambda^{B G}
$$

and thus Assumption 5 assures that $\alpha_{E}^{\star}<\alpha_{D}^{\star}$. Comparative statics result are obtained using the equivalent of expression (12)

$$
\frac{\partial \alpha_{a}^{\star}}{\partial y}=\frac{\Omega_{y}^{b} \Omega_{\alpha_{b}}^{a}-\Omega_{y}^{a} \Omega_{\alpha_{b}}^{b}}{\Omega_{\alpha_{a}}^{a} \Omega_{\alpha_{b}}^{b}-\Omega_{\alpha_{b}}^{a} \Omega_{\alpha_{a}}^{b}}
$$

where Assumption 5 guarantees that $\Omega_{\alpha_{E}}^{E} \Omega_{\alpha_{D}}^{D}-\Omega_{\alpha_{D}}^{E} \Omega_{\alpha_{E}}^{D}>0$. Since $\Omega_{\Lambda_{a}^{W G}}^{a}<0, \Omega_{\Lambda_{b}^{W G}}^{a}=0$ and $\Omega_{\Lambda^{B G}}^{a}<0$ for each $a \neq b=E, D$, part (ii) and (iii) straightforwardly follow. Taking the derivative of $\Omega^{a}$ with respect to $\mu_{a}$ we observe that

$$
\begin{gathered}
\Omega_{\mu_{a}}^{a} \gtrless 0 \Longleftrightarrow \\
\left(\frac{\alpha_{a}}{x-\alpha_{a}}-\frac{\alpha_{b}}{x-\alpha_{b}}\right)\left[\mu_{a} \Lambda_{a}^{W G}+\mu_{b} \Lambda^{B G}\left(\frac{x-\alpha_{a}}{x-\alpha_{b}}\right)^{2}\right]-x\left(\mu_{E} \frac{1}{x-\alpha_{E}}+\mu_{D} \frac{1}{x-\alpha_{D}}\right)\left[\Lambda_{a}^{W G}-\Lambda^{B G}\left(\frac{x-\alpha_{a}}{x-\alpha_{b}}\right)^{2}\right] \gtrless 0
\end{gathered}
$$

for $a \neq b=E, D$. Since $\alpha_{E}^{\star}<\alpha_{D}^{\star}$, Assumption 5 implies that if $\frac{9}{16} \Lambda_{E}^{W G}>\Lambda^{B G}>\frac{16}{9} \Lambda_{D}^{W G}$, then $\Omega_{\mu_{E}}^{E}<0$ and $\Omega_{\mu_{D}}^{D}>0$ and consequently the results stated in the proposition follows. Part (v) of the proposition can be proved by following the steps of the proof of Proposition 5, part (iv), and by assuming that $\Lambda^{B G}$ is sufficiently small.

Proof of Proposition 8. We first show that $\frac{\partial S_{a}}{\partial \alpha_{a}^{\star}}<0$, for $a=E, D$, where $S_{E}$ and $S_{D}$ are given by (13) and (14), respectively. Consider first the case $a=E$ (the case where $a=D$ is perfectly

${ }^{23}$ Taking the derivative of $\Omega^{a}$ with respect to $\alpha_{b}$ we obtain that $\Omega_{\alpha_{b}}^{a} \gtrless 0$ if $\frac{\mu_{a}}{2 \mu_{a} \frac{x-\alpha_{a}}{x-\alpha_{b}}+\mu_{b}\left(\frac{x-\alpha_{a}}{x-\alpha_{b}}\right)^{2}} \gtrless \frac{\Lambda^{B G}}{\Lambda_{a}^{W G}}$, for $a \neq b=E, D$. Since $\frac{\Lambda^{B G}}{\Lambda_{D}^{W G}}>1$, it follows that $\Omega_{\alpha_{E}}^{D}<0$. On the other hand, since $\alpha_{E}<\alpha_{D}$, it follows that

$$
\frac{\mu_{E}}{2 \mu_{E} \frac{x-\alpha_{E}}{x-\alpha_{D}}+\mu_{D}\left(\frac{x-\alpha_{E}}{x-\alpha_{D}}\right)^{2}}>\frac{\mu_{E}}{2 \mu_{E} \frac{x}{x-1}+\mu_{D}\left(\frac{x}{x-1}\right)^{2}}>\frac{\mu_{E}}{2 \mu_{E}+\mu_{D}}=\frac{\mu_{E}}{1+\mu_{E}} .
$$

Assumption 5 that $\frac{\mu_{E}}{1+\mu_{E}}>\frac{\Lambda^{B G}}{\Lambda_{E}^{W G}}$ guarantees that $\Omega_{\alpha_{D}}^{E}>0$. 
symmetric). Taking the derivative of $S_{E}$ with respect to $\alpha_{E}^{\star}$, we obtain that $\frac{\partial S_{E}}{\partial \alpha_{E}^{\star}} \leq 0$ if (15) is satisfied. Substituting the FOC (20) into the left-hand-side of this inequality and simplifying terms, the inequality reads

$$
\left[\mu_{E} \Lambda_{E}^{W G}+\mu_{D} \Lambda^{B G}\left(\frac{x-\alpha_{E}}{x-\alpha_{D}}\right)^{2}\right]<1
$$

which, since $\Lambda^{B G}<\frac{9}{16}$, is always satisfied.

Consider first the derivative of $S_{a}$ with respect to $\Lambda_{a}^{W G}$, for $a=E, D$, which is given by the expression in (16). Note that $\frac{\partial S_{a}}{\partial \alpha_{a}^{\star}} \frac{\partial \alpha_{a}^{\star}}{\partial \Lambda_{a}^{W G}} \geq 0$, for each $a=E, D$. Since $\frac{\partial S_{D}}{\partial \alpha_{E}^{\star}} \frac{\partial \alpha_{E}^{\star}}{\partial \Lambda_{D}^{W G}}>0$ it follows that $\frac{d S_{D}}{d \Lambda_{D}^{W G}}>0$. On the other hand the sign of $\frac{d S_{E}}{d \Lambda_{E}^{W G}}$ is ambiguous, since the first term in (16) is positive while the second one, $\frac{\partial S_{E}}{\partial \alpha_{D}^{\star}} \frac{\partial \alpha_{D}^{\star}}{\partial \Lambda_{E}^{W G}}$, is negative. For very small values of $\Lambda_{E}^{W G}$, according to Assumption 5 , also $\Lambda^{B G}$ is very small. Hence, in the limit of $\Lambda^{B G} \rightarrow 0, \Lambda_{E}^{W G} \rightarrow 0$ and $\Lambda_{D}^{W G} \rightarrow 0$, where $\alpha_{D}^{\star} \rightarrow 1$ and $\alpha_{E}^{\star} \rightarrow 1$, we have that $\Omega_{\alpha_{E}}^{D} \rightarrow 0$ and since $\Omega_{\Lambda_{E}^{W G}}^{D}=0$, it follows that $\frac{\partial \alpha_{D}^{\star}}{\partial \Lambda_{E}^{W G}} \rightarrow 0$. Consequently for small values of $\Lambda_{E}^{W G}$ the first term in (16) dominates the second one, and therefore $\frac{d S_{E}}{d \Lambda_{E}^{W G}}>0$. If $\Lambda_{E}^{W G}=1$, then by the envelop theorem $\frac{\partial S_{a}}{\partial \alpha_{a}^{\star}}=0$. By continuity, for large values of $\Lambda_{E}^{W G}, \frac{\partial S_{a}}{\partial \alpha_{a}^{\star}}$ is small and therefore the first term in (16) dominates the second one, and consequently $\frac{d S_{E}}{d \Lambda_{E}^{W G}}<0$.

Consider next the derivative of $S_{a}$ with respect to $\Lambda_{b}^{W G}$, for $b \neq a=E, D$, which is given by the expression in (17). Note that $\frac{\partial S_{a}}{\partial \alpha_{b}^{\star}} \frac{\partial \alpha_{b}^{\star}}{\partial \Lambda_{b}^{W G}}>0$. Since $\frac{\partial S_{E}}{\partial \alpha_{E}^{\star}} \frac{\partial \alpha_{E}^{\star}}{\partial \Lambda_{D}^{W G}}>0$, it follows that $\frac{d S_{E}}{d \Lambda_{D}^{W G}}>0$. On the other hand, since $\frac{\partial S_{D}}{\partial \alpha_{D}^{\star}} \frac{\partial \alpha_{D}^{\star}}{\partial \Lambda_{E}^{W G}}<0, \frac{d S_{D}}{d \Lambda_{E}^{W G}}$ is ambiguous. Under the assumption that both $\Lambda_{D}^{W G}$ and $\Lambda^{B G}$ are small, one obtains that $\frac{d S_{D}}{d \Lambda_{E}^{W G}}>0$. Since $\frac{\partial \alpha_{E}^{\star}}{\partial \Lambda^{B G}}<0$ and the sign of $\frac{\partial \alpha_{D}^{\star}}{\partial \Lambda^{B G}}$ is ambiguous, if follows that $\frac{\partial S_{a}}{\partial \alpha_{E}^{\star}} \frac{\partial \alpha_{E}^{\star}}{\partial \Lambda^{B G}}>0$ and that the sign of $\frac{\partial S_{a}}{\partial \alpha_{D}^{\star}} \frac{\partial \alpha_{D}^{\star}}{\partial \Lambda^{B G}}$ is ambiguous for $a=E, D$. For sufficiently small values of $\Lambda^{B G}$ and $\Lambda_{D}^{W G}, \frac{\partial \alpha_{D}^{\star}}{\partial \Lambda^{B G}}$ is negligible small, and thus $\frac{d S_{a}}{d \Lambda^{B G}}>0$.

Finally, consider the derivative of $S_{a}$ with respect to $\mu_{a}$, for $a=E, D$, which is given by the expression in (18). Since the first two terms in (18) are positive, while the third term is negligible small for small values of $\Lambda_{D}^{W G}$ and $\Lambda^{B G}$, it follows that $\frac{d S_{E}}{d \mu_{E}}>0$; (ii) since the first and third terms in (18) are negative, while the second term is negligible for small values of $\Lambda_{D}^{W G}$ and $\Lambda^{B G}$, it follows that $\frac{d S_{D}}{d \mu_{D}}<0$. 


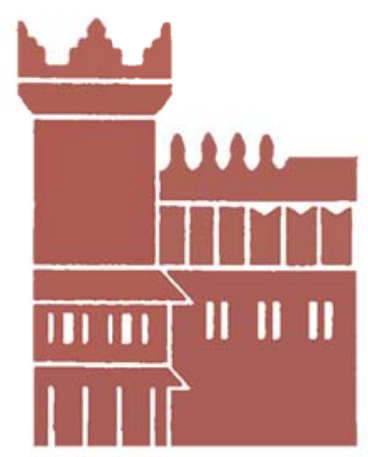

Alma Mater Studiorum - Università di Bologna DEPARTMENT OF ECONOMICS

Strada Maggiore 45

40125 Bologna - Italy

Tel. +39051 2092604

Fax +390512092664

http://www.dse.unibo.it 